\title{
Study Identifier
}

National Cancer Institute

\section{Source}

National Cancer Institute. Study Identifier. NCI Thesaurus. Code C83082.

A sequence of characters used to identify, name, or characterize the study. 